\title{
Considerações sobre a representação visual das zoonoses na contemporaneidade: contágio interespécies e antropocentrismo
}

\section{Maria Berbara'}

Resumo: Zoonoses são doenças infecciosas causadas por patógenos que saltam de não-humanos para humanos. Algumas das doenças zoonóticas mais conhecidas e perigosas são ebola, "doença da vaca louca" (EEB), gripe aviária, gripe suína, raiva, e, mais recentemente, Covid-19. Este artigo traça algumas considerações sobre a representação visual das zoonoses na contemporaneidade e estabelece uma breve análise comparativa sobre a relação entre humanos e seu alimento em dois modelos de consumo cárneo: o abate ritual entre os Tupinambá nos séculos XVI e XVII e a atual produção pecuária industrial.

Palavras-chave: Zoonoses. Covid-19. Tupinambá. Iconografia animal.

\section{Considerations on the visual representations of zoonoses in contemporaneity: cross-species transmission and anthropocentrism}

\begin{abstract}
Zoonoses are infectious diseases caused by pathogens that jump from non-humans to humans. Some of the most well-known and dangerous zoonotic diseases are Ebola virus disease, "mad cow disease" (BSE), bird flu, swine influenza, rabies, and, more recently, COVID-19. This paper analyses the visual representation of zoonoses in contemporaneity and develops a brief comparative analysis about the relationship between humans and their food in two models of meat consumption: the ritual slaughter amongst the Tupinamba in the 16th and 17 th centuries, and current industrial livestock production.
\end{abstract}

Keywords: Zoonoses. Covid-19. Tupinamba. Animal iconography. 
Dois trabalhadores, vestindo um imaculado uniforme branco coberto por um longo e ensanguentado avental, observam, de costas, uma pilha de vacas recentemente abatidas (Fig. 1). São homens sem rosto, tão anônimos quanto os animais sacrificados. A foto - cuja associação às terríveis imagens de cadáveres desnudos e empilhados que, desde a segunda guerra mundial, assombram a humanidade, é quase inevitável ${ }^{1}$ - foi tirada em março de 1997 na Bavária, Alemanha, em plena epidemia de encefalopatia espongiforme bovina (EEB), vulgarmente conhecida como doença da vaca louca.

Figura 1 Açougueiros diante de uma pilha de animais abatidos para prevenir um surto de EEB na

Bavária, Alemanha. 21 de março de 1997 Crédito: AP - Fonte: https://www.theguardian. com/environment/ng-interactive/2020/sep/15/ covid-farm-animals-and-pandemics-diseases-that-changed-the-world, acesso em 7 de outubro de 2020.

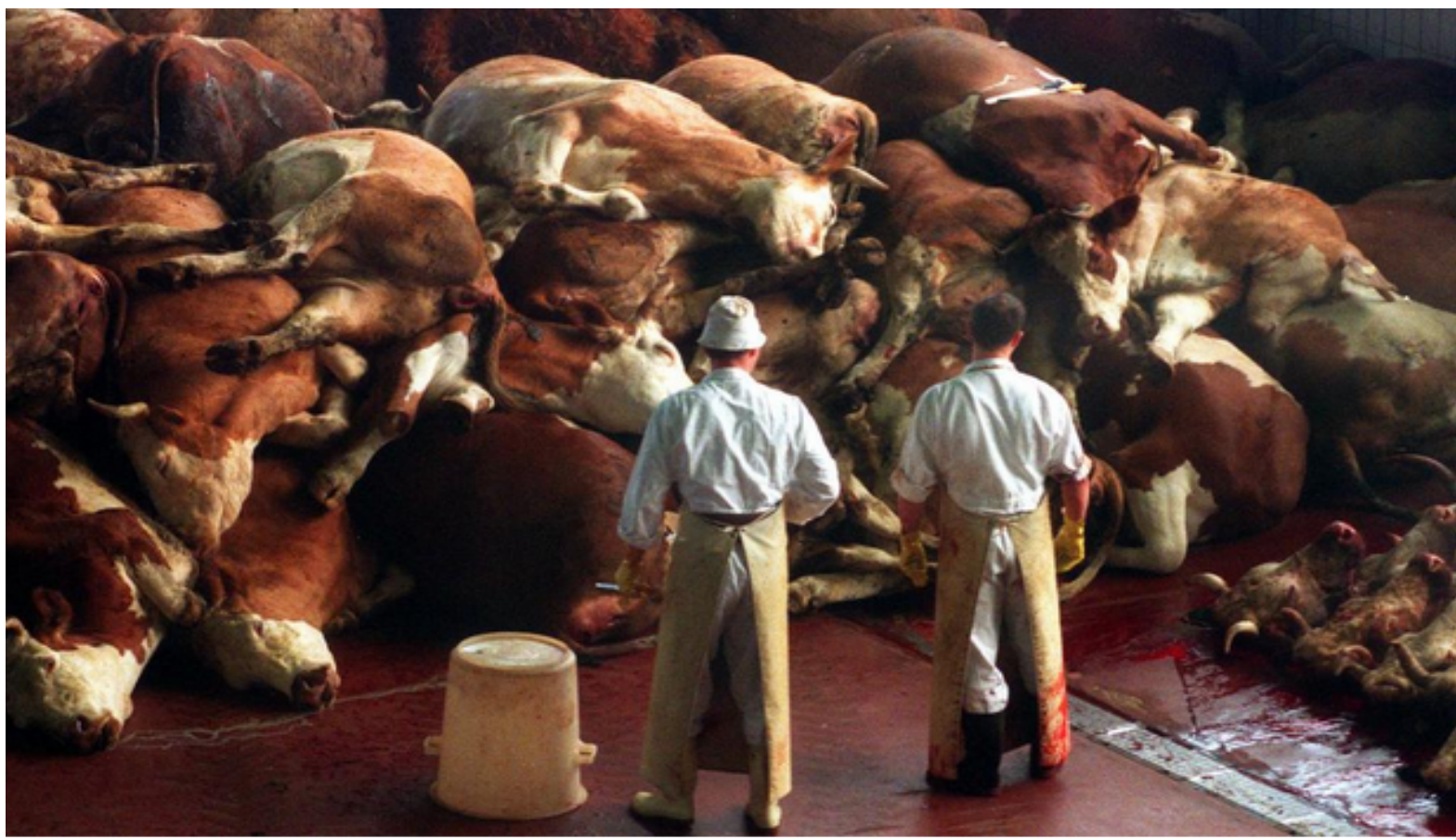

1 A imagem, de fato, foi vinculada ao livro "Eternal Treblinka. Our Treatment of Animals and the Holocaust", de Charles Patterson (Nova York: Lantern Books, 2002). Um dos argumentos centrais do livro é que a objetificação e escravização de animais em escala industrial abriu uma brecha civilizacional para formas similares de tratar seres humanos. De acordo com a tradição judaico-cristã, o ser humano ocupa um lugar especial na criação e, portanto, é lícito que disponha livremente de outros animais. A indiferença que o ser humano demonstra por eles, assim como as intervenções às quais são com frequência submetidos - como, por exemplo, a castração, a separação de filhotes das mães, variadas formas de mutilação, entre outros - tem, para o autor, uma relação intrínseca com formas de dominação e controle dentro das sociedades humanas - aí incluídos sexismo, racismo, discriminação de classe, etc. No início da segunda parte do livro (p. 50), Patterson recorda o filósofo de ascendência judia Theodor Adorno, que, em suas Minima Moralia (§68) paraleliza a indiferença de humanos diante da morte de animais e outros humanos: "A obstinação com que este desvia de si esse olhar [de um animal mortalmente ferido] - "é apenas um animal" - repete-se sem exceção nas crueldades infligidas aos homens, nas quais os executores têm continuamente de se persuadir do "é só um animal" [...]" (tradução de Artur Morão). 
Ainda no final dos anos 1980, estudos demonstraram que a ingestão de carne bovina contaminada poderia causar enfermidades a outras espécies, entre as quais felinos e ruminantes selvagens. Foi constatado, ainda, que a doença é transmissível ao ser humano, ao qual pode causar a doença de Creutzfeldt-Jakob (nvCJD). Para impedir o contágio interespécie, 4,4 milhões de animais foram preventivamente sacrificados somente no Reino Unido - o foco central da doença. Por outro lado, estima-se que, nos doze países onde foi identificada, a doença de Creutzfeldt-Jakob tenha vitimado 231 pessoas desde $1996 .{ }^{2}$

A "doença da vaca louca" é apenas uma das enfermidades que ameaçaram o homo sapiens nos últimos dois séculos. Animais envolvidos em eventos zoonóticos relacionam-se, majoritariamente, à agricultura industrial: tuberculose bovina, gripe aviária e gripe suína são alguns exemplos de contágio entre animais industrialmente criados para o abate e seres humanos. Um relatório publicado em julho de 2020 pelo Programa das Nações Unidas para o Meio Ambiente estabeleceu uma relação direta entre o aumento das enfermidades zoonóticas, a destruição antropogênica do meio-ambiente e a agropecuária industrial. ${ }^{3}$

Figura 2 Xilogravura da Verdadeira História... [Wahrhaftige Historia...] de Hans Staden. Marburg, 1557. (C)Biblioteca Brasiliana Guita e José Mindlin - (BBM) - Disponível em: https://digital.bbm.usp. $\mathrm{br} / \mathrm{handle} / \mathrm{bbm} / 4570$ (acesso em 7 de outubro de 2020).

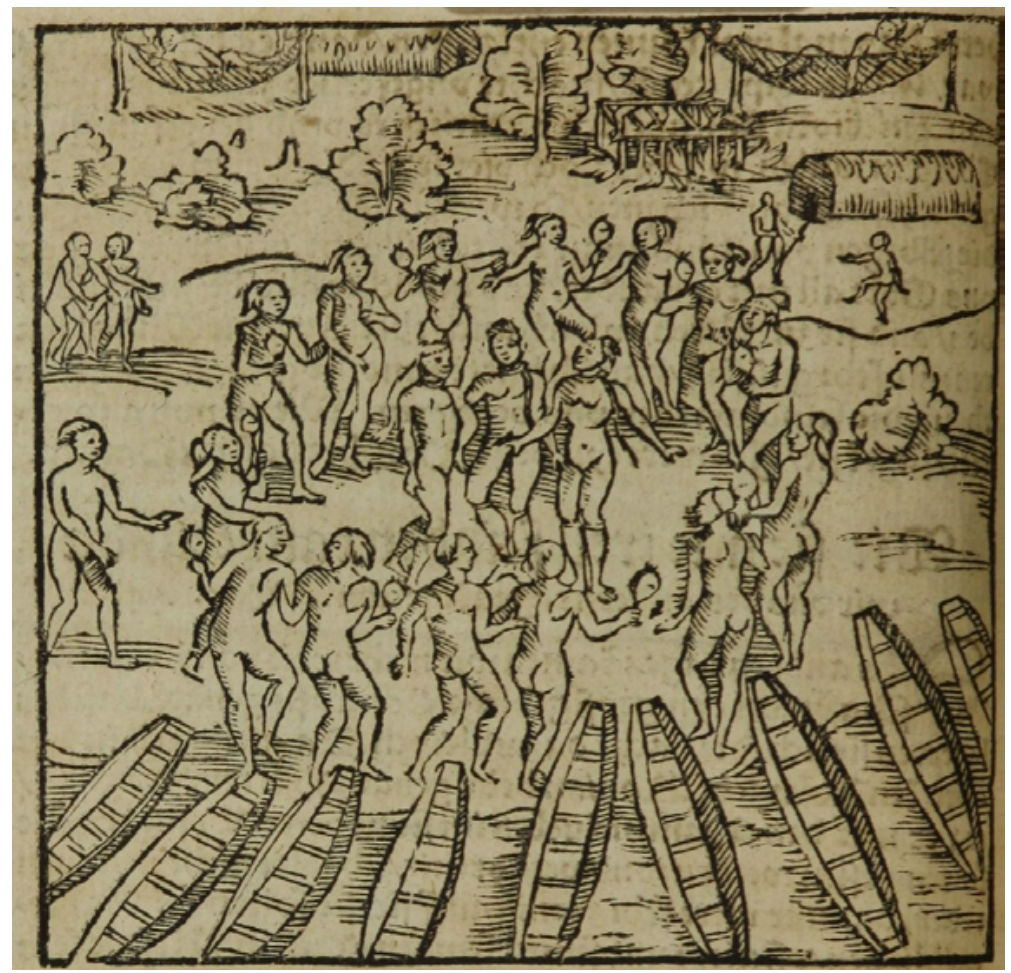

2 Ver https://www.cdc.gov/prions/bse/about.html; https://www.bbc.com/news/uk-scotland-north-east-orkney-shetland-45954225 e https://www.oie.int/animal-health-in-the-world/bse-specific-data/. Acesso em 13 de outubro de 2020.

3 https://www.unenvironment.org/resources/report/preventing-future-zoonotic-disease-outbreaks-protecting-environment-animals-and, acesso em 15 de outubro de 2020. 
Em forte contraste com o anonimato expressado pela fotografia examinada ao início deste artigo - o qual se repete em inúmeras outras, como na figura 7 abaixo - distintas sociedades americanas nativas expressam o vínculo estreito entre o caçador, o animal abatido e os membros da comunidade que o consomem. Examinemos brevemente uma célebre passagem da Verdadeira História, de Hans Staden, na qual o alemão - que, segundo seu próprio relato, havia sido capturado por uma comunidade Tupinambá em meados do século XVI e nela vivido por vários meses - relata uma conversa que teve com o líder Cunhambebe enquanto este último comia carne humana:

Comia de uma perna, segurou-a diante da boca e perguntou-me se também queria comer. Respondi: 'Um animal irracional não come um outro parceiro, e um homem deve devorar um outro homem?'. Mordeu-a então e disse: 'Jauára ichê'. Sou um jaguar. Está gostoso. ${ }^{4}$

A ilustração aqui reproduzida (Fig. 2) representa a dança tupinambá ao redor de seus inimigos, a qual é narrada no mesmo capítulo:

Os selvagens reuniram-se e formaram um grande cerco dentro do qual ficaram os prisioneiros. Estes tiveram de cantar todos juntos e agitar os ídolos, os maracás. Em seguida, um após o outro falou destemidamente, dizendo: "Sim, nós saímos, como fazem os homens corajosos, para capturá-los e comê-los, a vocês, nossos inimigos. Mas vocês foram mais fortes e nos capturaram. Não pedimos nada. Os combatentes valorosos morrem nas terras de seus inimigos. E nossa terra ainda é grande. Os nossos ainda se vingarão em vocês." Então os outros responderam: "Vocês já eliminaram muitos dos nossos. Queremos vingá-los em vocês."

Já Viveiros de Castro havia chamado a atenção para essa passagem, indicando como a fala de Cunhambebe invertera radicalmente a perspectiva cultural sobre sua própria ação: naquele momento, ele era um jaguar, e seu alimento, um homem. ${ }^{5}$ Gabriel Soares de Souza, por sua vez, indicara que os Tupi muitas vezes aprisionavam o jaguar, ou onça (panthera onca, Fig. 3), e abatiam-no no terreiro de modo análogo à execução ritual de seus contrários. ${ }^{6}$ Também o jesuíta Fernão Cardim relata como a onça capturada podia sofrer destino igual ao do inimigo: "[...] são os Índios tão ferozes que há índio que

4 Capítulo 43 da edição de Eduardo Bueno (tradução de Angel Bojadsen).

5 Eduardo Viveiros de Castro, Araweté, os deuses canibais. Rio de Janeiro: Jorge Zahar, 1986, p. 625 .

6 Apud Adone Agnolin, "Antropofagia ritual e identidade cultural entre os Tupinambá". Revista de Antropologia [online], 2002, vol.45, n.1, pp. 12-13. 
arremete com huma, e tem mão nella e depois a matão em terreiro com fazem aos contrários, tomando nome, e fazendo-lhes todas as ceremonias que fazem aos mesmos contrários". André Thevet, o cosmógrafo francês que acompanhou Villegagnon em sua expedição fundadora da França Antártica, na baia de Guanabara, relatou em sua Cosmographia (1575) como a onça, depois de sua captura, podia ser trazida para o terreiro e paramentada "como um prisioneiro que irá ser comido"; em seguida, seus algozes pedem-lhe que Ihes perdoe e não queira vingar-se dos homens. ${ }^{8}$

Figura 3

Jaguar, ou onça

[panthera onca]

A maioria das onças

é de cor acastanhada

coberta por rosetas. Cerca de $6 \%$ indivíduos, nas populações selvagens, possuem a pelagem completamente negra (melanismo) (c) Photocech/Getty Images

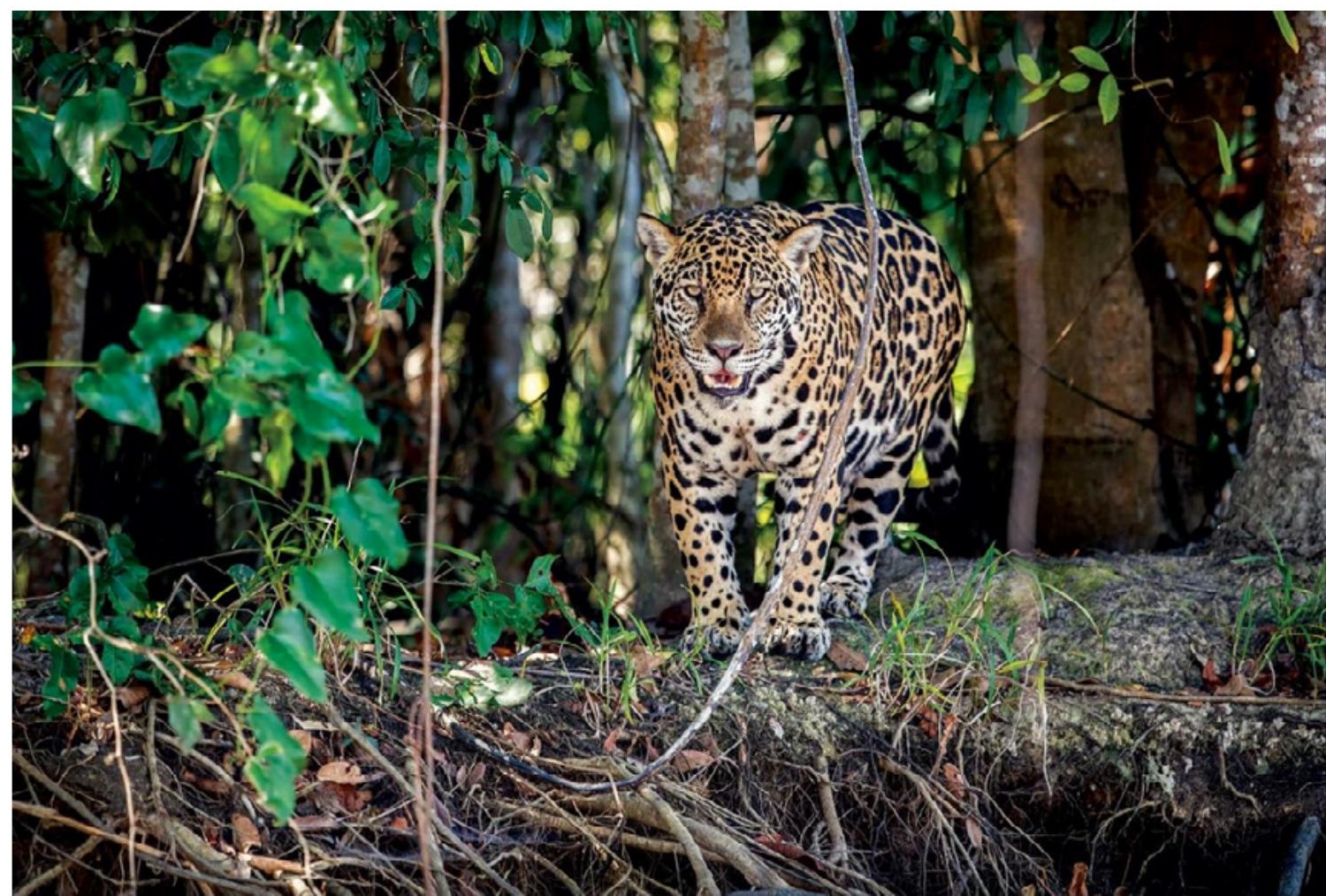

O habitat natural da onça antes das invasões europeias compreendia desde o sul dos atuais Estados Unidos até o norte da atual Argentina. ${ }^{9}$ Ela aparece em rituais, símbolos e objetos artísticos de praticamente todas as sociedades americanas que habitavam essas regiões - aí incluídas,

7 P. 38 da edição de 1925 dos Tratados da Terra e Gente do Brasil (Rio de Janeiro: Editores J. Leite). O jesuíta português escreveu o livro, provavelmente, entre 1583 e 1601, durante sua primeira estadia no atual Brasil. A edição pode ser consultada na Biblioteca Brasiliana Guita e José Mindlin: https://digital.bbm.usp.br/handle/bbm/4788 (acesso em 5 de outubro de 2020).

8 Apud Manuela Carneiro da Cunha e Eduardo Viveiros de Castro, "Vingança e Temporalidade: os Tupinambá". Journal de la Societé des américanistes, vol. 71, 1985, p. 206, nota 8.

9 No momento presente, a espécie está em decrescimento e ocorre em apenas $50 \%$ do seu alcance histórico. Para dados estatísticos, ver The IUCN Red List of Threatened Species: https://www.iucnredlist.org/species/15953/123791436\#geographic-range (acesso em 10 de outubro de 2020). 
entre muitas outras, a mexica, moche, chavín e maia. ${ }^{10} \mathrm{Na}$ iconografia olmeca, por exemplo, destaca-se a figura do "jaguar-homem", e os maias - para quem a habilidade felina de enxergar no escuro dava ao jaguar a capacidade de mover-se entre mundos - incluíam-no com frequência em relevos, pinturas e esculturas. Solidamente plantada no topo da cadeia alimentar, a onça é frequentemente associada à força, majestosidade e poder, e, mesmo na atualidade, não são incomuns mitologias que incluem híbridos entre elas e humanos: na província mexicana de Guerrero (Chilapa), para que fiquemos em apenas exemplo, os festivais da chuva recriam cenas de batalhas rituais das quais participam pessoas vestidas de onça.

Adone Agnolin, em seu artigo "Antropofagia ritual e identidade cultural entre os Tupinambá", pesquisa o significado do jaguar na cultura mitopoética tupinambá, analisando, para isso, as versões míticas em que aparece performaticamente descrita a função mitológica do jaguar (ou onça) em sociedades tupinambá. Embora não seja possível, como admite o autor, exaurir as numerosas versões míticas do jaguar, "O que podemos fazer aqui é destacar, entre essas numerosas referências, algumas características que possam oferecer algumas trilhas: elas devem nos permitir seguir as pegadas do jaguar em sua função de instrumento cultural Tupi e procurar, através desse instrumento, algumas possibilidades de melhor entender o significado da prática antropofágica para a cultura Tupi". ${ }^{11}$ Agnolin recorda como o jesuíta Jácome Monteiro, em sua "Relação da Província do Brasil", escreveu que os indígenas pensavam que o jaguar havia sido gente em outros tempos; o estatuto "humano" do animal evidenciava-se na execução performática, tendo tomado nome e sido paramentado como um prisioneiro de guerra, a qual, como vimos, é referida por mais de uma fonte literária. Existe, portanto, uma relação orgânica e equilibrada entre o ser humano e o jaguar, na qual este último tanto é um concorrente do homem - comendo os mesmos animais que ele - quanto o espelho que o torna, a um só tempo, caça e caçador.

A relação entre indígena e jaguar, ou onça, aparece na iconografia do Padre José de Anchieta, o jesuíta canário que viveu no Brasil entre 1553 - quan-

10 Para uma coletânea de textos sobre o simbolismo felino no continente americano ver Nicholas J. Saunders (org.), Icons of Power: Feline Symbolism in the Americas. Londres e Nova York: Routledge, 1998.

11 Agnolin, "Antropofagia ritual" p. 10. 
do contava apenas 19 anos de idade - e sua morte, em 1597. Além de missionário extremamente ativo, Anchieta escreveu ainda a primeira gramática da língua Tupi (1595) e o poema épico Gesta de Mem de Sá, além de autos e epístolas. O Evangelho das Selvas, de Benedito Calixto (1893), retrata-o, descalço e em plena floresta, convertendo uma onça bravia (Fig. 4); a lenda segundo a qual Anchieta teria amansado um jaguar, de fato, aparece de várias formas em suas biografias, incluindo até mesmo versões mais recentes, como a de Celso Vieira. ${ }^{12} \mathrm{~A}$ onça, portanto, aparece como uma metonímia válida para a representação de todo o território a ser cristianizado - aí incluídos seus habitantes.

Figura 4

Benedito Calixto Evangelho nas Selvas, 1893

Óleo sobre tela, $58,5 \times 70 \mathrm{~cm}$

Pinacoteca do

Estado de São Paulo (c) Wikimedia Commons

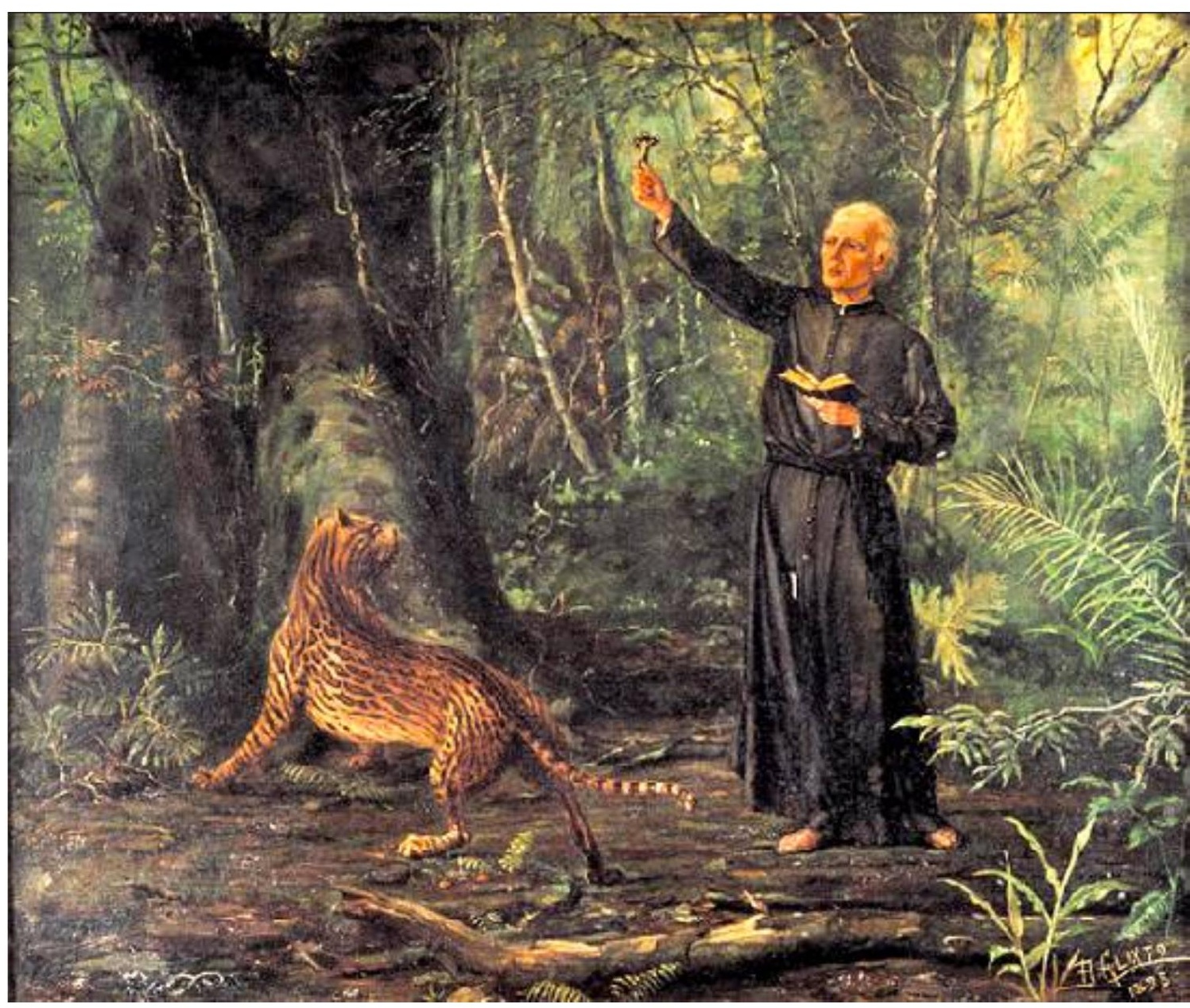

12 Um artigo de 2015 analisa o papel do jaguar em práticas de conversão jesuíticas nos séculos $\mathrm{XVII}$ e XVIII. O texto busca demonstrar que, embora religiosos cristãos com frequência associassem jaguares a rituais xamânicos, os animais também podiam assumir uma função positiva, sob a ótica jesuíta, em processos de conversão. Ver Karin Vélez, "'By means of tigers': Jaguars as Agents of Conversion in Jesuit Mission Records of Paraguay and the Moxos, 1600-1768". Church History, vol. 84, nr. 4, 2015, pp. 768-806. A biografia de Celso Vieira, publicada originalmente nos anos 1920, teve sua terceira edição (1949) digitalizada pela Biblioteca Digital de Obras Raras da UFRJ e pode ser acessada em: https://bdor.sibi.ufrj.br/bitstream/doc/348/1/262\%20PDF\%20-\%200CR\%20-\%20RED.pdf. 
Os dois exemplos indicados acima - o sacrifício ritual da onça entre os Tupinambá e o abate em massa de animais na Europa do século $X X$ - revelam modos radicalmente opostos de consumir carne, e, por extensão, da relação que o ser humano estabelece com outros animais. No universo Tupi, como se viu, há uma fluidez natural entre o que, contemporaneamente, chamaríamos diferentes espécies: quem come hoje, pode ser comido amanhã, e é na aceitação quase estoica dessa certeza que o mundo se mantém em saudável movimento.

Retornemos, agora, ao universo do contágio. A atual pandemia Covid-19, como bem se sabe, é de origem zoonótica, isso é, saltou de outro animal provavelmente o morcego - para o homo sapiens. ${ }^{13}$ Segundo dados da Organização Mundial da Saúde, estima-se que, globalmente, ocorram cerca de um bilhão de casos de doenças zoonóticas por ano entre humanos. Dos 30 novos patógenos que foram detectados nas últimas três décadas, 75\% tiveram origem em animais. Esses novos patógenos que não cessam de surgir são imprevisíveis: não se sabe onde vão se produzir, como se transmitirão, e que efeitos terão sobre a saúde humana. ${ }^{14}$ Como escreveu Luiz Marques em um recente artigo sobre pandemias e zoonoses, "[... o o aquecimento global, o desmatamento, a destruição dos habitats selvagens, a domesticação e a criação de aves e mamíferos em escala industrial destroem o equilíbrio evolutivo entre as espécies, facilitando as condições para saltos desses vírus de uma espécie a outra, inclusive a nossa". ${ }^{15}$

13 Pesquisas recentes indicam que a SARS-CoV-2 se relaciona, mais especificamente, ao morcego Rhinolophus. Ver Alice Latinne et al., "Origin and cross-species transmission of bat coronaviruses in China". Nature Communicatins, 11, 2020. Acesso online em https://www.nature.com/articles/ s41467-020-17687-3 (12 de outubro de 2020). Todos os CoVs que infectam humanos, de resto, são zoonóticos.

14 Cfr. http://www.emro.who.int/about-who/rc61/zoonotic-diseases.html (acesso em 6 de outubro de 2020).

15 Luiz Marques, "A pandemia incide no ano mais importante da história da humanidade. Serão as próximas zoonoses gestadas no Brasil?" Em https://www.unicamp.br/unicamp/noticias/2020/05/05/pandemia-incide-no-ano-mais-importante-da-historia-da-humanidade-serao-proximas, acesso em 12 de outubro de 2020. 
Figura 5

Imagem ilustrativa de doenças zoonóticas no site do CDC Centers for Disease Control and Prevention dos Estados Unidos Disponível em: https://www.cdc. gov/onehealth/images/zoonotic-diseases-spread-between-animals-and-people.jpg - acesso em 6 de outubro de 2020

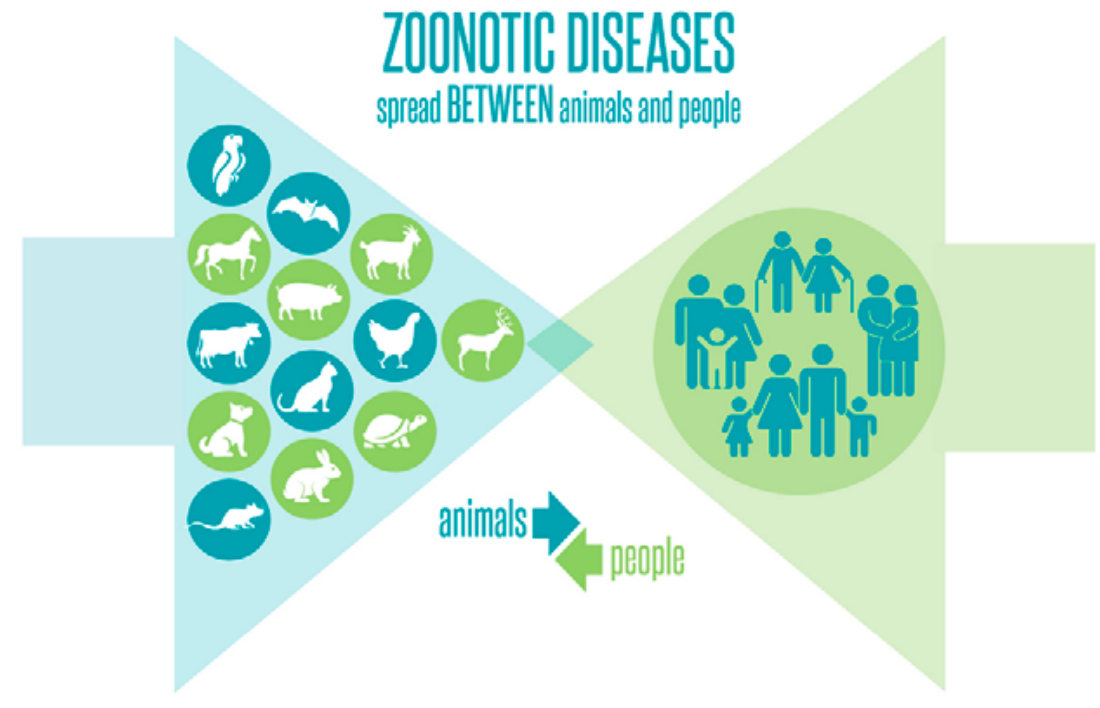

S. CDC

Uma breve análise da imagem acompanhando a aba sobre doenças zoonóticas do CDC, Centers for Disease Control and Prevention dos Estados Unidos (Fig. 5), mostra-se reveladora da desequilibrada relação que o ser humano estabelece com outros animais: duas flechas apontadas uma contra a outra incluem diversos círculos representando várias espécies de vertebrados; na flecha do lado direito, um único círculo engloba diferentes agrupações tradicionais familiares, enquanto, na esquerda, diversos círculos representam o perfil não individualizado de animais silvestres e domesticados.

Figura 6 Diversas representações esquemáticas de doenças zoonóticas disponíveis e replicadas em múltiplos sites (outubro de 2020)
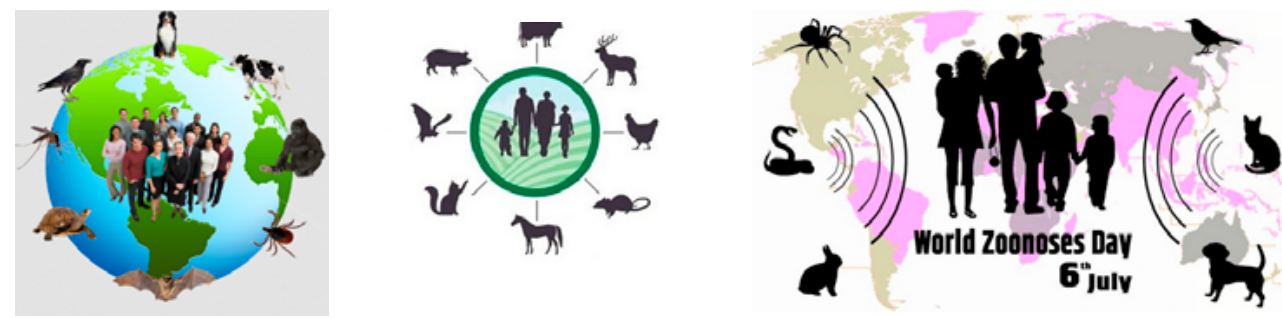

Em outras representações visuais de zoonoses (Fig. 6), famílias e indivíduos humanos são rodeados por outros animais. Nessas imagens, seres humanos são não apenas centralizados, mas, também, têm as suas relações sociais e/ou rasgos individuais representados - contrariamente aos animais que, isolados, aparecem em escala uniformizada. Imagens desse tipo revelam uma percepção claramente desequilibrada do lugar ocupado pelo homo sapiens no reino animal. Embora as ciências da vida tenham, ao longo do último século, demonstrado solidamente a senciência de animais 
não-humanos ${ }^{16}$ - isso é, sua capacidade de sentir e, por extensão, estabelecer relações sociais que incluam afeto, medo, etc. - representações esquemáticas das zoonoses consistentemente expressam uma visão antropocêntrica na qual humanos são não apenas hierarquicamente superiores, mas, também, os únicos capazes de sentir e viver em sociedade.

Em um artigo recente, o intelectual argentino José Emílio Burucúa recorda Lévi-Strauss ao refletir sobre como a cisão radical entre o humano e o animal, prevalente na cultura hegemônica contemporânea, corrompeu o próprio humanismo. Para promover uma reconciliação com a natureza e, assim, impedir não apenas a destruição de outras espécies, mas também a nossa, Burucúa postula "um humanimalismo que considere as origens e destinos comuns que animais humanos temos com os demais seres semoventes, sencientes e pensantes com os quais herdamos as terras, as águas e o ar.". ${ }^{17}$

Figura 7

Fileiras de visons sacrificados na

Dinamarca por causa de uma variante do Sar-CoV-2

(novembro de 2020)

- Crédito: Mads Claus Rasmussen / EFE - Fonte: https://brasil.elpais.com/ internacional/2020-11-07/ assim-e-o-coronavirus-que-teve-mutacao-na-dinamar-

ca.html - acesso em 9 de novembro de 2020

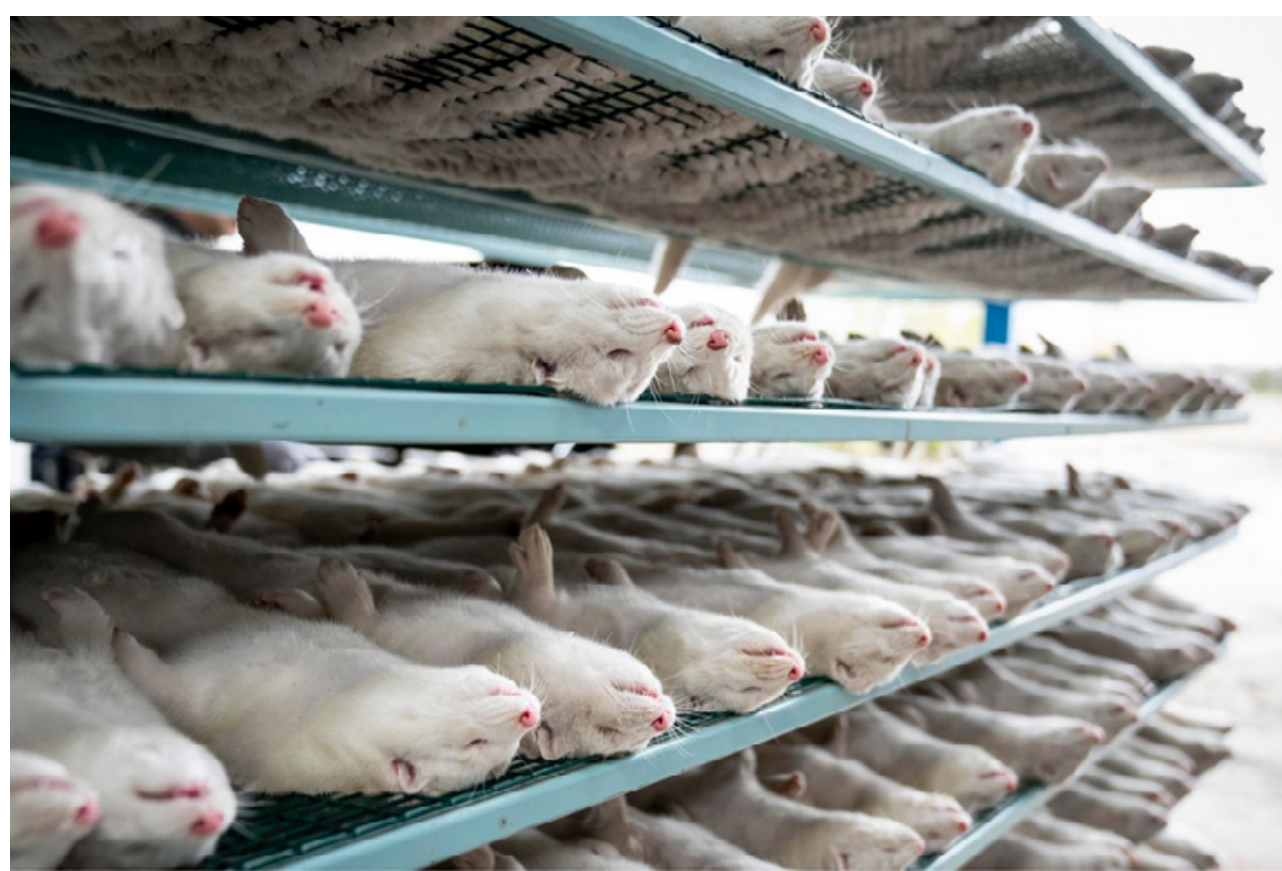

16 Veja-se, por exemplo, o periódico aberto "Animal Sentience. An Interdisciplinary Journal of Animal Feeling”, o qual reúne artigos acadêmicos de distintas áreas - aí incluídas a biologia, psicologia, direito e filosofia, entre outras - em torno da questão da senciência animal. Todos os artigos podem ser lidos gratuitamente em https://www.wellbeingintlstudiesrepository.org/animsent/about.html (acesso em 7 de outubro de 2020).

17 José Emílio Burucúa, "Pintar y mirar um cuadro para conocer, humanimalismo para regressar a la vida em tempos catastróficos". In Porvenir. La Cutura en la post pandemia. Buenos Aires: Fundación Medifé, 2020, pp. 47-48 (tradução minha). 
Enquanto persistir a visão utilitária dos demais animais, e enquanto o desmatamento e a agropecuária continuarem minando a biodiversidade e gerando concentrações altamente densas e antinaturais de espécies exploradas pelo ser humano, zoonoses surgirão e ameaçarão tanto humanos quanto outros animais: muito recentemente, de fato, a Dinamarca anunciou o abate de entre 15 e 17 milhões de visons por causa de uma nova mutação do coronavírus Sars-CoV-2 (Fig. 7). ${ }^{18}$ Nesse sentido, recordar relações mais equilibradas entre nós e outras espécies praticadas por sociedades muito diferentes da nossa pode dar-nos esperança e livrar-nos da espada de Dâmocles que, cada vez mais próxima, mantém nossa existência por um fio.

\section{Referências}

ADORNO, Theodor. Minima Moralia. Lisboa: Edições 70, 1993. Tradução de Artur Morão.

AGNOLIN, Adone. "Antropofagia ritual e identidade cultural entre os Tupinambá". Revista de Antropologia [online], 2002, vol. 45, n. 1

BURUCÚA, José Emílio. "Pintar y mirar um cuadro para conocer, humanimalismo para regressar a la vida em tempos catastróficos". In Porvenir. La Cutura en la post pandemia. Buenos Aires: Fundación Medifé, 2020

CARDIM, Fernão. Tratados da terra e da gente do Brasil. Rio de Janeiro: Editores J. Leite, 1925

CARNEIRO DA CUNHA, Manuela, e VIVEIROS DE CASTRO, Eduardo. "Vingança e Temporalidade: os Tupinambá". Journal de la Societé des américanistes, vol. 71, 1985

MARQUES, Luiz. "A pandemia incide no ano mais importante da história da humanidade. Serão as próximas zoonoses gestadas no Brasil?". Jornal da Unicamp, 5 de maio de 2020. Acessível em: https://www.unicamp.br/ unicamp/noticias/2020/05/05/pandemia-incide-no-ano-mais-importante-da-historia-da-humanidade-serao-proximas

18 Milhões de animais já haviam sido sacrificados, pelo mesmo motivo, na Espanha e na Holanda. Ver https://www.bbc.com/portuguese/internacional-54830493 e https://www.nationalgeographic.com/animals/2020/11/denmark-mink-culling/ (acesso em 9 de novembro de 2020). 
PATTERSON, Charles. Eternal Treblinka. Our Treatment of Animals and the Holocaust. Nova York: Lantern Books, 2002

SAUNDERS, Nicholas (org.). Icons of Power: Feline Symbolism in the Americas. Londres e Nova York: Routledge, 1998

STADEN, Hans. Duas viagens ao Brasil (título da edição portuguesa). Porto Alegre: L\&PM, 2007. Tradução de Angel Bojadsen

VÉLEZ, Karin. "'By means of tigers': Jaguars as Agents of Conversion in Jesuit Mission Records of Paraguay and the Moxos, 1600-1768". Church History, vol. 84, nr. 4, 2015

VIVEIROS DE CASTRO, Eduardo. Araweté, os deuses canibais. Rio de Janeiro: Jorge Zahar, 1986

Recebido e aceito em 24 de março de 2021.

Este é um artigo publicado em acesso aberto sob uma licença Creative Commons

(cc) Br 